\title{
O DIREITO DE CONSULTA DOS POVOS INDÍGENAS: INCIDÊNCIA DOS DIREITOS DA INFORMAÇÃO E PARTICIPAÇÁO NO LICENCIAMENTO AMBIENTAL EM TERRAS INDÍGENAS
}

THE RIGHTS OF CONSULTATION OF INDIGENOUS PEOPLE: IMPACT OF INFORMATION

RIGHTS AND PARTICIPATION IN ENVIRONMENTAL LICENSING IN INDIGENOUS LANDS

Nathália Santos Veras

Mestre pelo Programa de Pós-Graduação em Sociedade e Fronteiras (PPGSOF) da Universidade Federal de Roraima (UFRR). Especialista em Direito Civil e Processual Civil, pelo Centro Universitário UNISEB (Centro Universitário do Instituto de Ensino Superior COC) nathalia_veras@hotmail.com

Iara Loureto Calheiros

Mestre em Segurança Pública, Direitos Humanos e Cidadania pela Universidade Estadual de Roraima UERR. Especialista em Direito Público adviaracalheiros@hotmail.com

Sylvia Amélia Cantanhede

Mestre em Segurança Pública, Direitos Humanos e Cidadania pela UERR Especialista em Direito Processual Civil pela Universidade Anhanguera (UNIDERP sylvia_catanhede@hotmail.com

\section{RESUMO}

O presente artigo aborda a questão da garantia dos direitos à informação e participação no licenciamento ambiental em terras indígenas por meio do direito de consulta. Utilizandose da pesquisa qualitativa, do método dedutivo e dos procedimentos informados pelas pesquisas bibliográfica e documental, pretende-se discutir a importância do direito à consulta aos povos indígenas no processo de licenciamento como meio efetivo para assegurar os direitos à informação e participação, bem como seus direitos coletivos em geral. Não há consenso com relação à consulta às comunidades indígenas, vista, em geral, como não vinculante, o que acarreta a garantia apenas formal e não efetiva desse direito. Embora seja inviável defender uma vinculação absoluta ao resultado da consulta, esta tampouco pode ser vista apenas como um rito necessário ao licenciamento ambiental.

Palavras-chave: Informação. Participação. Direito à consulta. Povos Indígenas. Licenciamento Ambiental. 


\begin{abstract}
This article addresses the issue of guaranteeing the rights to information and participation in the process of environmental licensing in indigenous lands through the right of consultation. It is intended to discuss the importance of the right to consultation of indigenous peoples in the licensing process as an effective means to ensure the rights to information and participation, as well as to the as their collective rights in general. There is no consensus regarding the consultation of indigenous communities, seen in general as non-binding, which entails the only formal and non-effective guarantee of this right. Although it is not possible to defend an absolute linkage to the result of the consultation, it can not be seen only as a necessary rite for environmental licensing.
\end{abstract}

Keywords: Information. Participation. Right to consultation. Indigenous people. Environmental Licensing.

Data de submissão: 14/11/2018

Data de aceitação: 20/04/2020

\title{
SUMÁRIO
}

INTRODUÇÃO 1. DIREITO À INFORMAÇÃO E PARTICIPAÇÃO EM MATÉRIA DE MEIO AMMIENTE 2. DO DIREITO Ả CONSULTA DAS POPULAÇÓES INDÍGENAS 3. OS PROCEDIMENTOS EM LICENCIAMENTO AMBIENTAL EM TERRAS INDÍGENAS. CONSIDERAÇÓES FINAIS

\section{INTRODUÇÁO}

O presente artigo aborda a questão da garantia dos direitos à informação participação no licenciamento ambiental em terras indígenas por meio do direito de consulta. Pretende-se discutir a importância do direito à consulta aos povos indígenas no processo de licenciamento como meio efetivo para assegurar os direitos à informação e participação, bem como seus direitos coletivos em geral.

Trata-se de pesquisa qualitativa, que utiliza o método dedutivo e os procedimentos metodológicos das pesquisas bibliográfica e documental. Não se pretende esgotar o assunto, tampouco se ambiciona apontar soluções concretas. O intuito é contribuir para a reflexão sobre o direito de consulta aos povos indígenas no licenciamento ambiental de empreendimentos em suas terras.

Para alcançar o escopo do trabalho, abordam-se brevemente histórico dos direitos ao meio ambiente, informação e participação, relacionando-os nos marcos normativos internacionais e internos. Em seguida, trata-se sobre o direito à consulta, especificamente aos povos indígenas. Após, apresenta-se uma síntese sobre o procedimento de licenciamento ambiental em terras indígenas. Por fim, apresentam-se algumas consideraçóes a guisa de conclusóes. 


\section{DIREITO À INFORMAÇÃO E PARTICIPAÇÃO EM MATÉRIA DE MEIO AMBIENTE}

Ao meio ambiente, bem de uso comum do povo, relaciona-se a proteção dos espaços naturais e das paisagens, a preservação das espécies animais e vegetais, a manutenção do equilíbrio biológico, a proteçáo dos recursos naturais, a saúde, a seguridade, a salubridade pública, a conservação dos sítios e monumentos.

Nessa perspectiva, a Lei de Política Nacional do Meio Ambiente em seu inciso I, artigo 3º, o conceitua como "[...] o conjunto de condiçóes, leis, influências, alteraçóes e interaçóes de ordem física, química e biológica, que permite, abriga e rege a vida em todas as formas"

Tanto o meio ambiente como o direito à informação e participação são considerados direitos humanos de terceira geração, o que significa que são direitos reconhecidos pelo Estado recentemente. Em comparação, frequentemente apontam-se como marco dos direitos de primeira geração, tais como a liberdade e a igualdade, a Revolução Francesa, e dos de segunda geração, como a saúde e a educação, a Constituição Mexicana de 1917.

Com efeito, o meio ambiente enquanto direito a ser protegido começa a aparecer em tratados esparsos na década de 1940 e se consolida internacionalmente na década de 1960 como ramo do direito internacional. No Brasil, a proteção ao meio ambiente aparece timidamente na Constituição de 1934, inclusive culminando com o Código de Águas. Mas foi a Constituição de 1988 que pela primeira vez abordou amplamente o tema ${ }^{2}$, utilizando a expressão "meio ambiente" dezenove vezes, destinando todo um capítulo e o colocando expressamente na posição de direito, em seu artigo $225^{3}$, ao dizer que todos fazem jus a um meio ambiente equilibrado.

No tocante aos direitos da informação e da participação, que partem do pressuposto de que toda informação de matéria ambiental é de interesse coletivo, eles começam a serem assegurados na Convenção para Proteção da Flora, da Fauna e das Belezas Panorâmicas Naturais dos Países da América de 1940 e no Tratado da Antártica de 1959, mas foi a Declaração do Rio de Janeiro, da ECO-92, que os previu expressamente.

O Princípio 10 da Declaração do Rio de Janeiro declara que é importante assegurar a participação de todos os interessados em questóes ambientais, inclusive em processos decisórios. Como ferramentas, os Estados devem promover a educação ambiental e a participação, proporcionar acesso aos mecanismos judiciais e administrativos e disponibilizar

\footnotetext{
BRASIL. Lei no. 6.938, de 31 de agosto de 1981. Dispóe sobre a Política Nacional do Meio Ambiente, seus fins e mecanismos de formulação e aplicação, e dá outras providências.

2 LIMA, Francisco Arnaldo Rodrigues de. O direito ambiental nas constituiçóes do Brasil: um breve relato de sua construção histórica e a tese do artigo 225 CF/88 como cláusula pétrea. In: Âmbito Jurídico, Rio Grande, 2014.

3 "Art. 225. Todos têm direito ao meio ambiente ecologicamente equilibrado, bem de uso comum do povo e essencial à sadia qualidade de vida, impondo-se ao Poder Público e à coletividade o dever de defendê-lo e preservá-lo para as presentes e futuras geraçôes" (BRASIL. [Constituição (1988)]. Constituiçáo da República Federativa do Brasil de 1988. Disponível em: < http://www.planalto.gov.br/ccivil_03/constituicao/ constituicao.htm>. Acesso em: 28 jun. 2017).
} 
a todos informaçóes públicas acerca do meio ambiente ${ }^{4}$.

A Constituição de 1988 também deu destaque à informação e participação, concedendo, por exemplo, o direito a qualquer cidadão a propor ação popular (art. $5^{\circ}$, LXXIII) e o dever da coletividade de preservar o meio ambiente (art. 225) . Em decorrência desenvolveram-se normas para garantir a participação nas decisôes e fiscalização da política de meio ambiente, podendo-se citar como exemplo a Lei $n^{\circ} 9.795 / 1999^{6}$, que trata da educação ambiental, e a Lei $\mathrm{n}^{\circ} 10.650 / 2005^{7}$, que dispóe sobre o acesso público de informaçóes aos dados e informaçôes existentes nos órgãos e entidades integrantes do Sistema Nacional do Meio Ambiente - SISNAMA.

Neste cenário, o princípio da informação e participação em matéria de meio ambiente constitui um instrumento de democratização do acesso aos recursos ambientais, no qual é atribuída a toda a sociedade a obrigação de zelar pela qualidade do meio ambiente, em respeito ao direito universal ao ambiente ecologicamente equilibrado.

O chamado acesso à informação ambiental possui duas premissas básicas: primeiramente deve-se promover a conscientização dos cidadãos acerca das questóes ambientais de interesse geral, com vistas à melhoria da preservação ambiental, para que ocorra a participação pública nas tomadas de decisão que afetam a comunidade como um todo ${ }^{8}$.

É consenso que a política de proteção ambiental só terá sucesso quando houver disponibilidade de informação à coletividade no que diz respeito ao meio ambiente e aos empreendimentos que possam prejudicá-los, sendo o Poder Público importante propagador desses dados.

E ainda, para que a participação ambiental mediante a informação seja de maneira efetiva, tendo como por implicação o fortalecimento da educação ambiental, é requisito indispensável que as informaçóes disponibilizadas, sejam de maneira simples para que a compreensão dos dados seja facilitada. Pode ser que por este meio, seja possível a almejada mudança de atitudes perante o tratamento dos recursos naturais.

A informação ambiental possui caráter difuso, o qual não necessita de comprovação de in-

\footnotetext{
"Princípio 10. A melhor maneira de tratar as questôes ambientais é assegurar a participação, no nível apropriado, de todos os cidadãos interessados. No nível nacional, cada indivíduo terá acesso adequado às informaçóes relativas ao meio ambiente de que disponham as autoridades públicas, inclusive informações acerca de materiais e atividades perigosas em suas comunidades, bem como a oportunidade de participar dos processos decisórios. Os Estados irão facilitar e estimular a conscientizaçáo e a participaçáo popular, colocando as informaçōes à disposição de todos. Será proporcionado o acesso efetivo a mecanismos judiciais e administrativos, inclusive no que se refere à compensação e reparação de danos": Declaração do Rio de Janeiro. In: Estudos Avançados, São Paulo, v. 6, n. 15, p. 153-159, Aug. 1992. Disponível em: <http://www.scielo.br/scielo. php?script=sci_arttext\&pid=S0103-40141992000200013\&lng=en\&nrm=iso $>$. Acesso em: 04 maio 2020.

5 BRASIL. [Constituição (1988)]. Constituição da República Federativa do Brasil de 1988.

$6 \quad$ Id. Lei $\mathbf{n}^{\circ}$ 9.795, de 27 de abril de 1999. Dispóe sobre a educação ambiental, institui a Política Nacional de Educação Ambiental e dá outras providências.

$7 \quad$ Id. Lei $\mathbf{n}^{\circ} \mathbf{1 0 . 6 5 0}$, de $\mathbf{1 6}$ de abril de 2003. Dispóe sobre o acesso público aos dados e informaçóes existentes nos órgáos e entidades integrantes do SISNAMA. .
}

8 AMADO, Frederico. Direito ambiental, 2017. 
teresse pessoal do informado, bastando à constatação de esclarecimentos relativos aos fins e razóes do pedido. Isso se deve ao fato de que autoridades que detém essas informaçóes, são apenas gestores de tais dados e não detentores ${ }^{9}$.

Assim, entendendo-se que o meio ambiente é direito coletivo, deve-se assegurar não apenas o acesso à informação, mas a participação no planejamento, implantação e fiscalização de políticas públicas. No que tange à populaçáo indígena aldeada, esses direitos, como será visto a seguir, é acompanhado do direito de consulta.

\section{DO DIREITO À CONSULTA DAS POPULAÇÓES INDÍGENAS}

Há certo consenso na ideia de desenvolvimento sustentável como sendo a forma de desenvolvimento que satisfaz as necessidades das geraçóes presentes sem comprometer o direito ao meio ambiente das geraçóes futuras. No entanto, não há qualquer consenso em como fazer políticas públicas sustáveis. Assim, as discussóes sobre o direito meio ambiente internacional são marcadas pela dicotomia entre desenvolvimento e preservação ambiental.

No que tange aos projetos dentro de terras indígenas, apresenta-se ainda uma segunda dicotomia entre o "direito dos povos indígenas e o direito do restante da população ao desenvolvimento", caracterizada por "uma tensão entre duas realidades segmentadas" 10. Muito dessa perspectiva deve-se ao processo histórico de violência aos povos indígenas desde o Brasil colônia, mas principalmente durante o regime militar, que difundiu a ideia de que esses povos precisavam ser "pacificados" para não prejudicarem a política desenvolvimentista, cujo lema era "Integrar para não Entregar".

Com efeito, mesmo as normas que pretendem indenizar as vítimas da ditadura, deixaram de considerar os direitos coletivos dos povos indígenas e não se efetivou uma política voltada à reconciliação própria dos períodos de transição. Como resultado, a violência sofrida por eles durante a Ditadura Militar repercute na violência experimentada até os dias atuais. Ainda hoje, os povos indígenas são vistos equivocadamente como um empecilho ao desenvolvimento e, se for possível dizer que a violência deixou de ser estrutural (parte intrínseca da política estatal), ainda é sistêmica e o ressentimento institucionalizado ${ }^{11}$.

Historicamente, a visão etnocêntrica, retirou dos povos indígenas até mesmo do direito de ser reconhecido como povo, uma vez que, com o surgimento do estado-nação, tomou-se o vocábulo povo como vínculo fictício que constituía a nação. Da mesma forma, a instituição de um governo civil, como única forma reconhecidamente legítima de organização política afastou a característica de povo dos povos indígenas. Nesse diapasão, o princípio moderno da autodeterminação passou a ser relacionado à soberania e à independência de

\footnotetext{
AMADO, Frederico. Direito ambiental, 2017.

10 ZUGMAN, Daniel Leib. O dever de consulta aos povos indígenas e a construçáo da usina de Belo Monte. In: RedGV, 2013, p. 98.

11 VERAS, Nathália Santos. O 60 Princípio de Chicago na ditadura militar brasileira: o caso das violações dos direitos dos povos indígenas. In: BRASIL. MINISTÉRIO PÚBLICO FEDERAL. Justiça de transição, direito à memória e à verdade: boas práticas, 2018.
} 
modo a ser atribuída aos Estados, e negada aos povos ${ }^{12}$.

Mesmo ao reconhecer os direitos dos povos indígenas, como explica Souza Júnior ${ }^{13}$, os Estados da América Latina, historicamente, os vinculam a uma área demarcada, muitas vezes dividindo o próprio povo. A área permanece sob a jurisdição e soberania do Estado e, no Brasil, sob sua propriedade. $\mathrm{O}$ autor ${ }^{14}$ afirma ainda que, embora a Constituição determine que o Estado proteja os bens dos povos indígenas, isso deve ser feito pelo regime de tutela.

Nesse contexto, o direito de consulta às populaçóes indígenas encontra resistência, sendo frequente o entendimento de que a obrigatoriedade é apenas da consulta, não existindo um direito ao veto ${ }^{15}$. Embora se defenda um processo pautado na boa-fé, em que os povos indígenas possam efetivamente influenciar as políticas públicas, a não vinculação ao resultado, fomenta a realização de consultas meramente formais e simuladas.

Não é à toa que a principal referência legislativa ao direito de consulta dos povos indígenas ainda é a Convenção n. 169 de 1989 da Organização Internacional do Trabalho (OIT), promulgada pelo Brasil pelo Decreto n. 5.051/2004 ${ }^{16}$ :

\section{Artigo 6은}

1. Ao aplicar as disposiçóes da presente Convenção, os governos deverão: a) consultar os povos interessados, mediante procedimentos apropriados e, particularmente, através de suas instituiçóes representativas, cada vez que sejam previstas medidas legislativas ou administrativas suscetíveis de afetá-los diretamente; b) estabelecer os meios através dos quais os povos interessados possam participar livremente, pelo menos na mesma medida que outros setores da populaçáo e em todos os níveis, na adoção de decisôes em instituições efetivas ou organismos administrativos e de outra natureza responsáveis pelas políticas e programas que lhes sejam concernentes; c) estabelecer os meios para o pleno desenvolvimento das instituiçóes e iniciativas dos povos e, nos casos apropriados, fornecer os recursos necessários para esse fim.

2. As consultas realizadas na aplicação desta Convenção deverão ser efetuadas com boa fé e de maneira apropriada às circunstâncias, com o objetivo de se chegar a um acordo e conseguir o consentimento acerca das medidas propostas.

Artigo 7은

1. Os povos interessados deverão ter o direito de escolher suas, pró-

\footnotetext{
12 NOGUEIRA, Caroline Barbosa Contente. A autodeterminaçáo dos povos indígenas frente ao Estado. Orientador: Carlos Frederico Marés de Souza Filho. 2016. Tese (Doutorado), 2016. .

13 SOUZA FILHO, Carlos Frederico Marés de. Prefácio. In: LADEIRA, Maria Inês. Espaço Geográfico Guarani Mbya: Significado, constituição e uso, 2008.

$14 \quad$ Id. $\mathrm{O}$ renascer dos povos indígenas para o direito, 1999.

15 QUANE, Helen. The rights of Indigenous Peoples and the Development Process. In: Human Rights Quarterly, Baltimore,MD, 2005, p. 652-682.

16 BRASIL. Decreto n. 5.051, de 19 de abril de 2004. Promulga a Convenção no 169 da Organização Internacional do Trabalho - OIT sobre Povos Indígenas e Tribais.
} 
prias prioridades no que diz respeito ao processo de desenvolvimento, na medida em que ele afete as suas vidas, crenças, instituiçóes e bem-estar espiritual, bem como as terras que ocupam ou utilizam de alguma forma, e de controlar, na medida do possível, o seu próprio desenvolvimento econômico, social e cultural. Além disso, esses povos deverão participar da formulação, aplicação e avaliaçáo dos planos e programas de desenvolvimento nacional e regional suscetíveis de afetá-los diretamente.

$[\ldots]$

A Convenção n. 169 da OIT ${ }^{17}$ adota o paradigma da multiculturalidade, abandonandose a perspectiva integracionista da Convenção n. $107^{18}$ e passando a considerar os povos indígenas como portadores de sua própria cultura, a qual merece náo apenas ser tolerada, mas respeitada e considerada pelo Estado em suas políticas públicas. Note-se que mesmo pretendendo ser multicultural, a Convenção n. 169 já traz em seu bojo regras que se aproximam mais da interculturalidade ${ }^{19}$.

A interculturalidade, conforme explica Damázio ${ }^{20}$, pressupóe "um tipo de sociedade em que as comunidades étnicas, os grupos sociais se reconhecem em suas diferenças e buscam uma mútua compreensão e valorização". Em síntese, enquanto a multiculturalidade é vista como "simplesmente duas culturas que se mesclam ou que se integram" 21 , a interculturalidade seria o diálogo entre as culturas.

A Declaração Universal de Direitos dos Povos Indígenas ${ }^{22}$, aprovada em 2007, e da qual o Brasil é signatário segue o mesmo paradigma, conforme se observa nos seguintes artigos:

Artigo 19. Os Estados consultarão e cooperarão de boa-fé com os povos indígenas interessados, por meio de suas instituiçóes representativas, a fim de obter seu consentimento livre, prévio e informado antes de adotar e aplicar medidas legislativas e administrativas que os afetem.

Artigo 32

Os povos indígenas têm o direito de determinar e de elaborar as prioridades e estratégias para o desenvolvimento ou a utilização de suas terras ou territórios e outros recursos.

17 BRASIL. Decreto n. 5.051, de 19 de abril de 2004. Promulga a Convenção no 169 da Organizaçáo Internacional do Trabalho - OIT sobre Povos Indígenas e Tribais.

18 ORGANIZAÇÁO INTERNACIONAL DO TRABALHO (OIT). Convençáo no 107 da OIT, de 05 de junho de 1957. Concernente à proteçâo e integração das populaçôes indígenas e outras populaçôes tribais e semitribais de países independentes.

19 VERAS, Nathália Santos. O 6o Princípio de Chicago na ditadura militar brasileira: o caso das violaçôes dos direitos dos povos indígenas. In: BRASIL. MINISTÉRIO PÚBLICO FEDERAL. Justiça de transiçáo, direito à memória e à verdade: boas práticas, 2018.

20 DAMÁZIO, Silveira Petter. Multiculturalismo versus interculturalismo: por uma proposta intercultural do Direito. In: Desenvolvimento em Questáo, 2008.

21 Id. Ibidem, p. 77.

22 ORGANIZAÇÃO DAS NAÇÓES UNIDAS (ONU). Declaraçáo das Naçóes Unidas sobre os Direitos dos Povos Indígenas. Rio de Janeiro: Naçóes Unidas, 2008. 
2. Os Estados celebrarão consultas e cooperarão de boa fé com os povos indígenas interessados, por meio de suas próprias instituiçóes representativas, a fim de obter seu consentimento livre e informado antes de aprovar qualquer projeto que afete suas terras ou territórios e outros recursos, particularmente em relação ao desenvolvimento, à utilização ou à exploração de recursos minerais, hídricos ou de outro tipo.

Obviamente não se defende o posicionamento radical de ingerência dos povos indígenas em suas terras, que no Brasil possuem o regime de usufruto. Note-se que o poder absoluto sobre imóveis não é conferido nem mesmo quando incide o instituto da propriedade. Por outro lado, afastar o caráter absoluto do poder dos povos indígenas sobre suas terras não é, de modo algum, irreconciliável com o caráter deliberativo e vinculante das consultas prévias. O que se defende é a adoçáo de mecanismos eficazes para consulta dos povos indígenas e, principalmente, que seja a consulta levada em consideraçăo.

Ainda são escassos no Brasil mecanismos capazes de diminuir as assimetrias entre os povos indígenas, Estado e empresas, sendo que a consulta, muitas vezes, apenas reforça a relação de dominação em razão do poder limitado de negociação e decisão $0^{23}$. Mesmo com as normas internacionais internalizadas pelo Brasil ainda faltam mecanismos para que o Brasil supere a posição etnocentrista e se torne um Estado intercultural.

Não resta dúvida que esse processo só poderá ser alcançado plenamente com o respeito do direito de consulta dos povos indígenas. Para isso, năo basta assegurá-lo formalmente. A participação indígena deve ser efetiva e, obviamente, considerada nos processos decisórios.

\section{OS PROCEDIMENTOS EM LICENCIAMENTO AMBIENTAL EM TERRAS INDÍGENAS}

O licenciamento ambiental é um instrumento da política de meio ambiente que visa verificar a viabilidade dos empreendimentos que possam causar impacto ambiental ${ }^{24}$. São vários os órgãos licenciadores ambientais (federal, estadual e municipal), mas, no caso, de empreendimento que afetem as terras indígenas, a Fundação Nacional do Índio (FUNAI), que é o órgão oficial para tratar das questōes indígenas, tem a obrigação de se manifestar em todo e qualquer licenciamento, estabelecendo diretrizes e analisando os estudos referentes aos impactos ambientais e socioculturais, ainda que preliminarmente ${ }^{25}$.

Nesses casos, a FUNAI é responsável por emitir o termo de referência do Estudo de Impacto Ambiental (EIA) e do Relatório de Impacto Ambiental (RIMA), que, após

\footnotetext{
23 RODRÍGUEZ-GARAVITO, César. Ethnicity.gov: Global Governance, Indigenous Peoples, and the Right to Prior Consultation in Social Minefields. In: Indiana Journal of Global Legal Studies, Bloomington,IN, Vol. 18, No. 1, Winter 2011, p. 263-305.

24 BRASIL. Conselho Nacional do Meio Ambiente (CONAMA). Resoluçáo do Conama no 237, de 19 de dezembro de 1997.

25 Id. Fundação Nacional do Índio. Licenciamento ambiental e comunidades indígenas. Programa de Comunicação Indígena UHE Belo Monte. Brasília: Ministério da Justiça, 2011.
} 
prontos, são levados para audiências públicas. Esta é a forma de consulta pública usual no processo de licenciamento e tem por finalidade expor aos interessados o conteúdo do produto e do seu RIMA, que reflete as conclusóes do EIA, dirimindo dúvidas e recolhendo as críticas a respeito ${ }^{26}$.

Baseada no fundamento constitucional do direito de informação, que decorre do princípio da participação da população, a audiência tem por objetivo expor às informaçóes dos resultados do RIMA às comunidades e/ou população local dos municípios afetados pelo empreendimento e, através disso, recolher críticas e sugestóes com relação à instalação da atividade local.

Um dos fatores para que a consulta seja efetiva é justamente a garantia de participação que, repise-se, não deve ser apenas formal. Assim, alguns pontos devem ser considerados na audiência pública: i) a representatividade dos povos indígenas, que precisa observar os povos atingidos e sua diversidade cultural; ii) a representatividade dos órgáos estatais, que depende do objeto e tipo de consulta, não sendo recomendável terceirizar a consulta a particulares; iii) a língua utilizada, permitindo a participação e manifestação; e iv) acompanhamento de especialistas, como antropólogos ${ }^{27}$.

Vale ressaltar que no licenciamento deve ser dada a devida atenção à avaliação dos impactos em relação aos conhecimentos e práticas tradicionais, bem como conhecimento imaterial, respeitando os direitos dos povos indígenas sobre o território e o uso sustentável dos recursos naturais. Por isso, as audiências devem ter participação de todos os povos atingidos e de forma que sejam legitimamente representados (representaçáo de líderes e associaçóes indígenas, entre outros).

Por isso também, as audiências públicas com as comunidades indígenas são realizadas pela própria FUNAI, que emite o parecer técnico para o órgão licenciador. Pode e deve haver a participação de outros órgãos estatais a depender do objeto e tipo de consulta, mas, tratando-se de povos indígenas, a atuação da FUNAI é indispensável. Por outro lado, a consulta prévia não deve ficar a cargo das empresas responsáveis pelos empreendimentos diante do interesse no projeto e, consequentemente, no alto risco de tornar a audiência pública um mero procedimento formal.

Assim, a proteção às terras indígenas, os questionamentos e dúvidas dos povos protegidos deverão ocorrer, fundamentalmente, em conformidade com o texto da própria Convenção n. $169^{28}$, por meio dos órgãos públicos institucionalmente destinados a tutelar tais interesses, respeitando-se não apenas as atribuiçóes regulares dos órgãos

\footnotetext{
26 Id. Conselho Nacional do Meio Ambiente (CONAMA). Resoluçáo do Conama no 9, de 03 de dezembro de 1987.

27 SOUZA FILHO, Carlos Frederico Marés de (Coord.) Estatuto dos Povos Indígenas: uma análise em face das determinaçóes constitucionais e internacionais. Curitiba: PUCPR, 2009. (Série Pensando o Direito no. 19/2009).

28 Id. Decreto n. 5.051, de 19 de abril de 2004. Promulga a Convenção nº 169 da Organização Internacional do Trabalho - OIT sobre Povos Indígenas e Tribais.
} 
licenciadores, mas ainda o procedimento inscrito na Resolução Conama n. 01/86 ${ }^{29}$ e Instruçóes Normativas da FUNAI.

Da mesma forma, é importante que os povos compreendam e possam expressar suas manifestaçóes de modo que as audiências públicas devem ser realizadas na língua materna ou contar com a ajuda de tradutores. Nesse caso, é preciso ter cuidado para, em razão das diferenças culturais, não causar erros de tradução que prejudiquem compreensão e, consequentemente, a participação. Por essa razão também é necessário o apoio de especialistas, como, por exemplo, antropólogos.

Pelo que já foi discorrido até o momento e como também esclarece Caporrino ${ }^{30}$, a consulta tem 5 (cinco) características, devendo ser: i) prévia; ii) livre; iii) informada; iv) de boafé; e v) culturalmente adequada. $\mathrm{O}$ autor explica que a consulta deve ocorrer previamente porque não se destina a que os povos indígenas digam apenas se aceitam ou não uma proposta já integralmente formatada, mas que possam apreciar a questão e participar do processo e decisão. Além disso, afirma que os Estados devem incentivar os povos a terem previamente protocolos de discussão e tomada de decisão.

$\mathrm{O}$ autor ${ }^{31}$ também discorre que a consulta também deve ser livre, sem barganhas, pressôes ou intimidaçóes, e, ainda, informada, de modo, que os povos indígenas saibam todos os fatores envolvidos, tanto favoráveis como negativos. Consequentemente, a consulta deve ser realizada de boa-fé, isto é, sem surpresas, omissóes, maldades, etc. Por fim, a consulta deve ser culturalmente adequada respeitando os processos de tomada de decisão dos povos indígenas.

Em havendo impacto ambiental previsto no EIA/RIMA sobre a terra indígena, elabora-se o Plano Básico Ambiental (PBA), o qual deve conter as açóes indicadas pela FUNAI em seu parecer. Importante observar que o PBA necessariamente precisa ser elaborado em conjunto com as comunidades indígenas, que, após finalizado, passa por nova análise da FUNAI, a qual, em seguida, envia o parecer técnico para o órgáo licenciador.

O próximo passo é a emissão da Licença de Instalação (LI), que autoriza o início do empreendimento. Começa-se então a execução do PBA, durante o qual se emitem relatórios técnicos ao órgão licenciador, FUNAI e outros órgãos interessados. A FUNAI é encarregada de analisar esses relatórios no que tange ao impacto sobre as comunidades indígenas e enviar ao órgão licenciador.

Observe-se que os dados sobre os possíveis impactos ambientais em comunidades afetadas pelos empreendimentos requerem um cuidado com a efetiva conservação ambiental. Considerando o crescente risco de dano ambiental em terras indígenas e a preocupação com a preservação do meio ambiente e dos costumes e tradiçóes das comunidades indí-

\footnotetext{
29 Id. Conselho Nacional do Meio Ambiente (CONAMA). Resoluçáo do Conama no 1, de 23 de janeiro de 1986.

30 CAPORRINO, Bruno Walter. Dos que flecham longe: o Protocolo de Consulta e Consentimento Wajápi. Orientador: Carlos Machado Dias Júnior. Dissertação (Mestrado em Antropologia Social). Universidade Federal do Amazonas: Manaus, 2019.

31 Id. Ibidem.
} 
genas potencialmente afetadas, justifica-se a participação intensa da FUNAI em todo o processo de licenciamento ambiental.

Posteriormente, estando a obra finalizada, é emitida a Licença de Operação (LO), permitindo o empreendimento funcionar, desde que as observaçóes da LI tenham sido cumpridas. Após, durante toda a execução do projeto, ao menos em tese, devem ser emitidos relatórios técnicos periódicos a serem fiscalizados pela FUNAI e pelo órgão licenciador.

O licenciamento ambiental em terras indígenas é preventivo, sendo o seu foco na proteção do meio ambiente, pelo uso racional dos recursos naturais e na proteção dos direitos individuais e coletivos dos povos indígenas, o que só é alcançado com a garantia da participação efetiva das comunidades indígenas afetadas pelo empreendimento e atividades sujeitas a licenciamento.

\section{CONSIDERAÇÓES FINAIS}

Tanto o meio ambiente como os a informação e participação são considerados direitos humanos. Nesse sentido, o acesso à informação e participação nas decisões de políticas públicas e empreendimentos ambientais são essenciais em uma democracia. Não obstante, com relação aos povos indígenas, apesar de terem esses direitos consagrados, ainda há resistência em considerar suas opinióes.

Essa resistência é resultado da política integracionista que ponderou não apenas no Brasil como em todo o mundo. A adoção da perspectiva multicultural data apenas do final da década de 1980, havendo resquícios fortes nas políticas públicas e no imaginário popular.

Não há consenso com relação à consulta às comunidades indígenas, vista, em geral, como não vinculante, o que acarreta a garantia apenas formal, e não efetiva desse direito. Embora seja inviável defender uma vinculação absoluta ao resultado da consulta, esta tampouco pode ser vista apenas como um rito necessário ao licenciamento ambiental e deve ter, em regra, caráter deliberativo e vinculante.

Diante da realidade que mantém o indígena em sua relação com a natureza, se faz necessário que os impactos ambientais sejam minimizados e/ou suprimidos no decorrer execução do empreendimento, sendo o licenciamento uma ferramenta de prevenção e a consulta um instrumento indispensável para proteção dos direitos dos povos indígenas.

\section{REFERÊNCIAS}

AMADO, Frederico. Direito ambiental. 5. ed., rev. e atual. Salvador: Editora JusPodivm, 2017.

BRASIL. Conselho Nacional do Meio Ambiente (CONAMA). Resoluçáo do Conama no 237, de 19 de dezembro de 1997. Disponível em: < http://www.mma.gov.br/port/conama/res/res97/ res23797.html >. Acesso em: 28 jun. 2017.

. Conselho Nacional do Meio Ambiente (CONAMA). Resoluçáo do Conama no $\mathbf{1}$, 
de 23 de janeiro de 1986. Disponível em: < https://www.ibama.gov.br/sophia/cnia/legislacao/ MMA/RE0001-230186.PDF>. Acesso em: 14 nov. 2018.

Conselho Nacional do Meio Ambiente (CONAMA). Resoluçáo do Conama no 9, de 03 de dezembro de 1987. Disponível em: < http://www.mma.gov.br/port/conama/res/res87/ res0987.html>. Acesso em: 28 jun. 2017.

Fundação Nacional do Índio. Licenciamento ambiental e comunidades indígenas. Programa de Comunicação Indígena UHE Belo Monte. Brasília: FUNAI, 2011. Disponível em: <http://www.mma.gov.br/port/conama/res/res87/res0987.html>. Acesso em: 28 jun. 2017.

[Constituição (1988)]. Constituição da República Federativa do Brasil de 1988. Brasília, DF: Presidência da República, [2017]. Disponível em: < http://www.planalto.gov.br/ ccivil_03/constituicao/constituicao.htm>. Acesso em: 28 jun. 2017.

. Decreto n. 5.051, de 19 de abril de 2004. Promulga a Convenção no 169 da Organização Internacional do Trabalho - OIT sobre Povos Indígenas e Tribais. Disponível em: <http://www. planalto.gov.br/ccivil_03/_ato2004-2006/2004/decreto/d5051.htm>. Acesso em: 01 maio 2017.

Lei no. 6.938, de 31 de agosto de 1981. Dispóe sobre a Política Nacional do Meio Ambiente, seus fins e mecanismos de formulação e aplicação, e dá outras providências. Disponível em: <http://www.planalto.gov.br/ccivil_03/leis/L6938.htm> Acesso em: 10 maio 2017.

. Lei $\mathbf{n}^{\circ}$ 9.795, de 27 de abril de 1999. Dispóe sobre a educação ambiental, institui a Política Nacional de Educação Ambiental e dá outras providências. Disponível em: < http://www. planalto.gov.br/ccivil_03/leis/L9795.htm> Acesso em: 10 maio 2017.

Lei $\mathrm{n}^{\circ} \mathbf{1 0 . 6 5 0}$, de 16 de abril de 2003. Dispóe sobre o acesso público aos dados e informaçôes existentes nos órgãos e entidades integrantes do SISNAMA. Disponível em: < http:// www.planalto.gov.br/ccivil_03/leis/2003/L10.650.htm> Acesso em: 10 maio 2017.

CAPORRINO, Bruno Walter. Dos que flecham longe: o Protocolo de Consulta e Consentimento Wajāpi. Orientador: Carlos Machado Dias Júnior. 2019. Dissertação (Mestrado em Antropologia Social). Universidade Federal do Amazonas, Manaus, 2019. Disponível em: <https://tede.ufam. edu.br/handle/tede/7735>. Acesso em: 02 maio 2020.

DAMÁZIO, Silveira Petter. Multiculturalismo versus interculturalismo: por uma proposta intercultural do Direito. In: Desenvolvimento em Questáo, Ijuí, v. 6, n.12, p.63-86, jul./dez. 2008. Disponível em: <http://www.redalyc.org/articulo.oa?id=75211183004>. Acesso em: 19 abr. 2017.

DECLARAÇÃO do Rio de Janeiro. In: Estudos Avançados, São Paulo, v. 6, n. 15, p. 153159, ago. 1992. Disponível em: <http://www.scielo.br/scielo.php?script=sci_arttext\&pid=S0103$40141992000200013 \& \operatorname{lng}=$ en\&nrm=iso $>$. Acesso em: 04 maio 2020.

LIMA, Francisco Arnaldo Rodrigues de. O direito ambiental nas constituiçóes do Brasil: um breve relato de sua construçáo histórica e a tese do artigo $225 \mathrm{CF} / 88$ como cláusula pétrea. In: Âmbito Jurídico, Rio Grande, XVII, n. 122, mar 2014. Disponível em: <http://ambito-juridico.com.br/ site/?n_link=revista_artigos_leitura\&artigo_id=14555>. Acesso em: 10 maio 2017.

NOGUEIRA, Caroline Barbosa Contente. A autodeterminaçáo dos povos indígenas frente ao Estado. Orientador: Carlos Frederico Marés de Souza Filho. 2016. Tese (Doutorado). Pontifícia Universidade Católica do Paraná, Curitiba, 2016. Disponível em: <https://www. academia.edu/37260294/A_AUTODETERMINA\%C3\%87\%C3\%83O_DOS_POVOS_ IND\%C3\%8DGENAS_FRENTE_AO_ESTADO?auto=download>. Acesso em: 02 maio 2020. 
ORGANIZAÇÃO INTERNACIONAL DO TRABALHO (OIT). Convençáo no 107 da OIT, de 05 de junho de 1957. Concernente à proteção e integraçáo das populaçôes indígenas e outras populaçóes tribais e semitribais de países independentes. Disponível em: $<$ https://www.oas.org/dil/ port $1957 \% 20$ Conven $\%$ C3\%A7\%C3\%A3o\%20sobre\%20Povos\%20Ind\%C3\%ADgenas\%20 e\%20Tribais.\%20(Conven\%C3\%A7\%C3\%A3o\%20OIT\%20n\%20\%C2\%BA\%20107).pdf>. Acesso em: 01 maio 2017.

ORGANIZAÇÃO DAS NAÇÓEES UNIDAS (ONU). Declaraçáo das Naçóes Unidas sobre os Direitos dos Povos Indígenas. Rio de Janeiro: Naçóes Unidas, 2008. Disponível em: < http:// www.un.org/esa/socdev/unpfii/documents/DRIPS_pt.pdf>. Acesso em: 11 jun. 2017.

QUANE, Helen. The rights of Indigenous Peoples and the Development Process. In: Human Rights Quarterly, Baltimore,MD, No27, 2005, p. 652-682. Disponível em: <https://www. umass.edu/legal/Benavides/Fall2005/397U/Readings\%20Legal\%20397U/13\%20Helen\%20 Quane.pdf>. Acesso em: 14 nov. 2018.

RODRÍGUEZ-GARAVITO, César. Ethnicity.gov: Global Governance, Indigenous Peoples, and the Right to Prior Consultation in Social Minefields. In: Indiana Journal of Global Legal Studies, Bloomington,IN, Vol. 18, No. 1, Winter 2011, p. 263-305. Disponível em: < http:// burawoy.berkeley.edu/Public\%20Sociology,\%20Live/Rodriguez.Global\%20Governance.pdf >. Acesso em: 14 nov. 2018.

SOUZA FILHO, Carlos Frederico Marés de (Coord.) Estatuto dos Povos Indígenas: uma análise em face das determinaçóes constitucionais e internacionais. Curitiba: PUCPR, 2009. (Série Pensando o Direito $\mathrm{n}^{\circ}$. 19/2009). Disponível em: <https://legado.justica.gov.br/seus-direitos/ elaboracao-legislativa/pensando-o-direito/publicacoes/anexos/19pensando_direito_relatorio. pdf>. Acesso em: 02 maio 2020.

SOUZA FILHO, Carlos Frederico Marés de. $\mathrm{O}$ renascer dos povos indígenas para o direito. $1^{\mathrm{a}}$ ed. $2^{a}$ tir. Curitiba: Juruá, 1999.

Prefácio. In: LADEIRA, Maria Inês. Espaço Geográfico Guarani Mbya: Significado, constituição e uso. Maringá: Eduem; São Paulo: Edusp, 2008.

VERAS, Nathália Santos. O 60 Princípio de Chicago na ditadura militar brasileira: o caso das violaçóes dos direitos dos povos indígenas. In: BRASIL. MINISTÉRIO PÚBLICO FEDERAL. Justiça de transiçáo, direito à memória e à verdade: boas práticas. Brasília: MPF, 2018. Disponível em: < http://www.mpf.mp.br/atuacao-tematica/ccr2/publicacoes/coletaneas-de-artigos/07_18_ coletanea_de_artigos_justica_de_transicao $>$. Acesso em: 14 nov. 2018.

ZUGMAN, Daniel Leib. O dever de consulta aos povos indígenas e a construção da usina de Belo Monte. In: RedGV, São Paulo, Ano 2, v.1, n. 3, junho de 2013. Disponível em: < http://bibliotecadigital. fgv.br/ojs/index.php/revdiscentegv/article/view/19610/18330 >. Acesso em: 28 jun. 2017.

GONÇALVES FILHO, Edilson Santana; ROCHA, Jorge Bheron; MAIA, Maurilio Casas. CUSTUS VULNERABILIS: A Defensoria Pública e o equilíbrio nas relaçóes político-jurídicas dos vulneráveis. Belo Horizonte. Editora CEI. 2020. 132 p. 